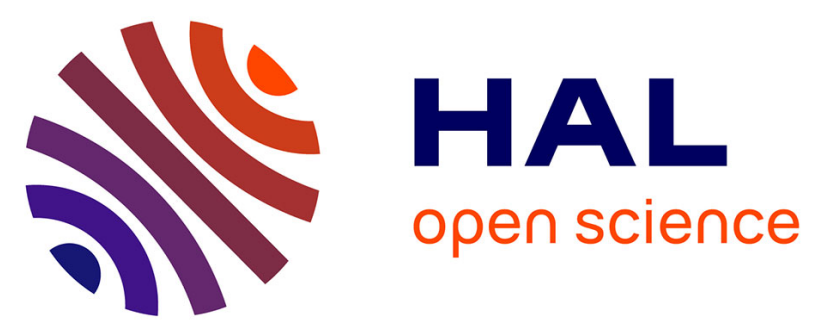

\title{
Crystal Structure of a Cross-reaction Complex between Fab F9.13.7 and Guinea Fowl Lysozyme
}

Julien Lescar, Matteo Pellegrini, Hélène Souchon, Diana Tello, Roberto J. Poljak, Norman Peterson, Mark Greene, Pedro M. Alzari

\section{To cite this version:}

Julien Lescar, Matteo Pellegrini, Hélène Souchon, Diana Tello, Roberto J. Poljak, et al.. Crystal Structure of a Cross-reaction Complex between Fab F9.13.7 and Guinea Fowl Lysozyme. Journal of Biological Chemistry, 1995, 270 (30), pp.18067-18076. 10.1074/jbc.270.30.18067 . pasteur-03136579

\section{HAL Id: pasteur-03136579}

https://hal-pasteur.archives-ouvertes.fr/pasteur-03136579

Submitted on 9 Feb 2021

HAL is a multi-disciplinary open access archive for the deposit and dissemination of scientific research documents, whether they are published or not. The documents may come from teaching and research institutions in France or abroad, or from public or private research centers.
L'archive ouverte pluridisciplinaire HAL, est destinée au dépôt et à la diffusion de documents scientifiques de niveau recherche, publiés ou non, émanant des établissements d'enseignement et de recherche français ou étrangers, des laboratoires publics ou privés.

\section{(c)(1)}

Distributed under a Creative Commons Attribution| 4.0 International License 


\title{
Crystal Structure of a Cross-reaction Complex between Fab F9.13.7 and Guinea Fowl Lysozyme*
}

(Received for publication, February 14, 1995, and in revised form, April 25, 1995)

\author{
Julien Lescar $\ddagger$, Matteo Pellegrini $\ddagger \S$, Hélène Souchon $\ddagger$, Diana Tello $\ddagger$, Roberto J. Poljak \\ Norman Peterson|, Mark Greene $\mid$, and Pedro M. Alzarił*** \\ From the $\ddagger$ Unité d'Immunologie Structurale and URA 359 CNRS, Département d'Immunologie, Institut Pasteur, 75724 \\ Paris Cedex 15, France and the $\|$ Department of Pathology and Laboratory Medicine, University of Pennsylvania, \\ Philadelphia, Pennsylvania 19104-6082
}

\begin{abstract}
The crystal structure of the complex between the cross-reacting antigen Guinea fowl lysozyme and the Fab from monoclonal antibody F9.13.7, raised against hen egg lysozyme, has been determined by x-ray diffraction to 3-^ resolution. The antibody interacts with exposed residues of an $\alpha$-helix and surrounding loops adjacent to the lysozyme active site cleft. The epitope of lysozyme bound by antibody F9.13.7 overlaps almost completely with that bound by antibody HyHEL10; the same 12 residues of the antigen interact with the two antibodies. The antibodies, however, have different combining sites with no sequence homology at any of their complementarity-determining regions and show a dissimilar pattern of cross-reactivity with heterologous antigens. Side chain mobility of epitope residues contributes to confer steric and electrostatic complementarity to differently shaped combining sites, allowing functional mimicry to occur. The capacity of two antibodies that have different fine specificities to bind the same area of the antigen emphasizes the operational character of the definition of an antigenic determinant. This example demonstrates that degenerate binding of the same structural motif does not require the existence of sequence homology or other chemical similarities between the different binding sites.
\end{abstract}

Antibody molecules convey a potentially unlimited molecular diversity and antigen-binding repertoire. Although the genetic elements and mechanisms underlying the generation of this functional and structural diversity have been characterized (Tonegawa, 1983), an understanding of the molecular principles that govern antibody specificity remains a major challenge. In this paper, we report the crystal structure of the cross-reaction complex between the antigen Guinea fowl lysozyme $(\mathrm{GEL})^{1}$ and the Fab fragment from the mAb F9.13.7,

* This work was supported in part by grants from the Institut Pasteur and from CNRS. The costs of publication of this article were defrayed in part by the payment of page charges. This article must therefore be hereby marked "advertisement" in accordance with 18 U.S.C. Section 1734 solely to indicate this fact.

The nucleotide sequence(s) reported in this paper has been submitted to the GenBank ${ }^{\mathrm{TM}} /$ EMBL Data Bank with accession number(s) U20819 and U20820.

The atomic coordinates (code 1FBI) have been deposited in the Protein Data Bank, Brookhaven National Laboratory, Upton, NY.

$\S$ Present address: Dept. of Physics, Stanford University, CA 94305 4090 .

I Supported by the Human Frontiers Science Program and the W. E. Elkins Professorship for 1994-1995 at the University of Maryland. Present address: CARB, 9600 Gudelsky Dr., Rockville, MD 20850.

** To whom correspondence should be addressed.

${ }^{1}$ The abbreviations used are: GEL, Guinea fowl lysozyme; mAb, monoclonal antibody; CDR, complementarity-determining region raised against $\mathrm{HEL}$.

Avian egg lysozymes have long served as model antigens for investigating the specificity of immune recognition (for review, see Benjamin et al. (1984)). Cross-reaction studies using panels of evolutionarily related avian lysozymes have identified amino acid residues and the general region of the antigen bound by specific mAbs. Using this test, the antibodies could be grouped by their binding specificities (Harper et al., 1987; Lavoie et al., 1992). Crystallographic analysis of several Fab-lysozyme complexes (Amit et al., 1986; Sheriff et al., 1987; Padlan et al., 1989; Chitarra et al., 1993; Braden et al., 1994) have extended these characterizations of antigenic determinants (or epitopes), and common features have emerged from these studies. 1) The lysozyme-antibody interfaces are large $\left(600-800 \AA^{2}\right)$ and highly complementary. 2) Both the $L$ and $H$ chains of antibodies make extensive contacts with lysozyme, and the specificity of binding is determined by the CDRs. 3) The contacting residues of lysozyme are discontinuous in sequence but form a contiguous surface. 4) van der Waals' interactions, hydrogen bonds, and, to a much lesser extent, salt bridges mediate the binding of antibodies to lysozyme. 5) Small conformational changes in the antibodies and in lysozyme take place upon complex formation. In addition, these x-ray studies indicated that antibody cross-reactivity results from interactions with epitopes that are shared by heterologous lysozymes or that are closely similar and can be contacted by the antibody with minor conformational rearrangements.

In the crystal structure of the cross-reaction complex between Fab F9.13.7 and the heterologous antigen GEL, we have found unexpectedly that the epitope bound by F9.13.7 nearly coincides with that bound by the anti-HEL mAb HyHEL10 (Padlan et al., 1989). However, mAbs F9.13.7 and HyHEL10 are structurally different in their $\mathrm{L}$ and $\mathrm{H}$ chains. We discuss how the two antibodies, with unrelated combining sites, achieve specific, high affinity binding to nearly the same epitope of lysozyme.

\section{MATERIALS AND METHODS}

Crystallization and Data Collection-Preparation of the proteins and crystallization of the complex have been described (Lescar et al., 1993). The crystals are monoclinic, space group $\mathrm{P} 2$, unit cell dimensions $a=$ $83.7 \AA, b=195.5 \AA c=50.2 \AA, \beta=108.5^{\circ}$, with two molecules of the complex in the asymmetric unit. Crystal instability upon irradiation precluded merging diffraction data from different crystals. A single data set for structure refinement was collected at $4{ }^{\circ} \mathrm{C}$ using a MARresearch image plate system and synchrotron radiation from beam line D23 at LURE, Orsay, France $(\lambda=0.986 \AA)$. A total of 111,931 measurements from 180 images $\left(\Delta \omega=1^{\circ}\right)$ were reduced to 30,232 unique

r.m.s., root mean square; HEL, hen lysozyme; JQL, Japanese quail lysozyme; PHL, pheasant lysozyme; L, light chain; H, heavy chain; L1, L2, L3, hypervariable regions of the light chain; $\mathrm{H} 1, \mathrm{H} 2, \mathrm{H} 3$, hypervariable regions of the heavy chain. 

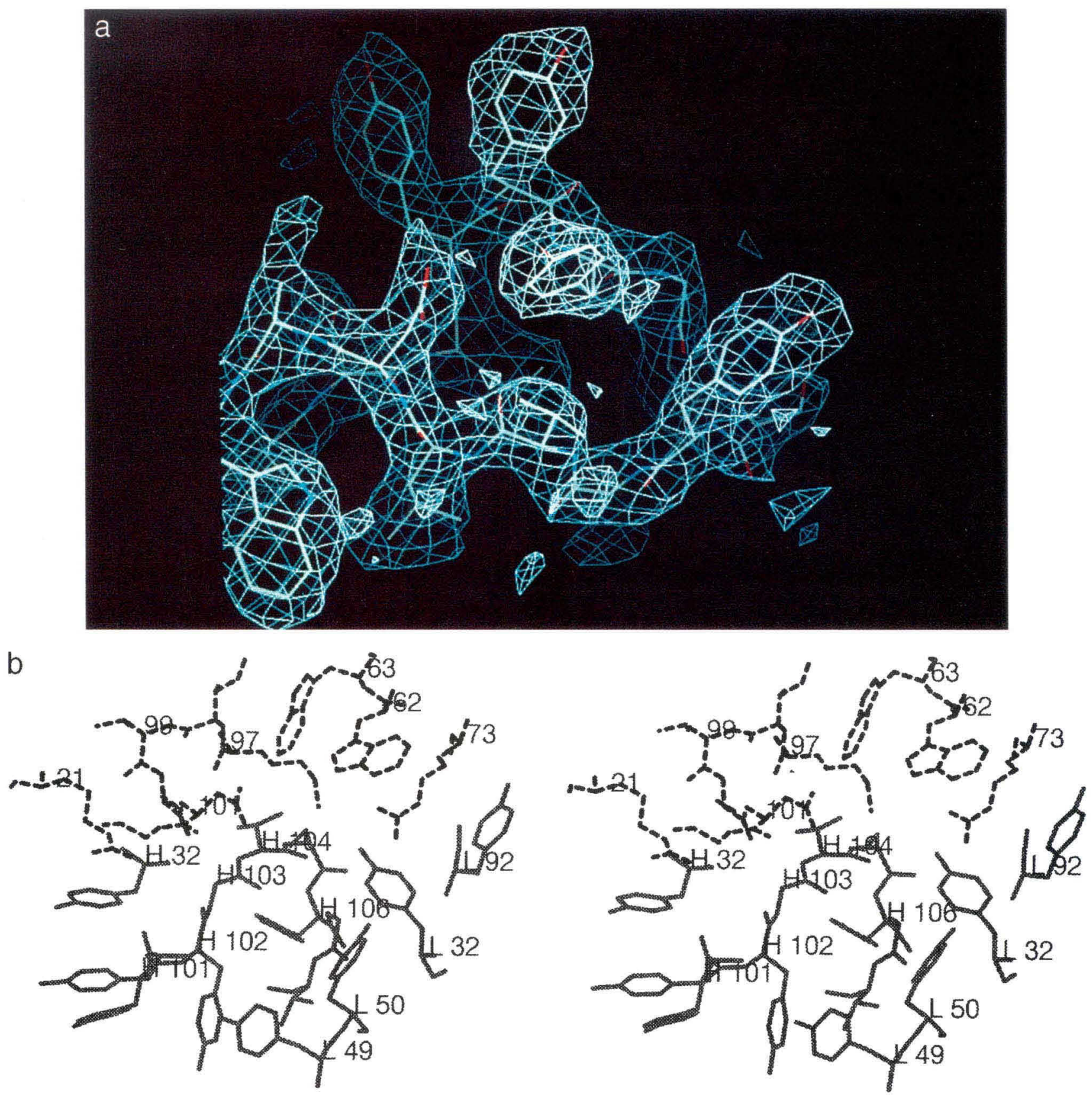

FIG. 1. $a$, electron density ( $2 F-F$ ) map contoured at $1 \sigma$ of the H3 hypervariable loop of F9.13.7. $b$, stereo view of the contacts made by H3 (solid lines) with lysozyme (dashed lines). Tyrosine residues of neighboring hypervariable loops making stacking interactions are also shown (see text).

intensities (95\% complete to 3 -A resolution) with the MOSFLM package (Leslie, 1990) and the CCP4 suite (SERC, 1986). The internal merging $R$-factor is $14 \%$ for all data to a nominal resolution of $3 \AA$ ( $11 \%$ for reflections with $F>\sigma(F)$ ).

Structure Determination and Refinement-The crystal structure was determined at 4-A resolution by molecular replacement methods using the program AMoRe (Navaza, 1994) as described previously (Lescar et al., 1993). The structures of unliganded GEL (Lescar et al., 1994), the variable dimer of Fab E225 (Bentley et al., 1990) and the constant dimer of Fab D1.3 (Fischmann et al., 1991) were used as independent search models. Real space averaging between the two independent copies of the complex (SKEW) (Bricogne, 1976) significantly improved the quality of the density map, allowing the unambiguous tracing of all the CDRs that had been omitted from the initial models. Refinement was carried out with XPLOR (Brünger et al., 1987), and model rebuilding was carried out with the programs FRODO (Jones, 1978) and QUANTA (Molecular Simulations Inc.). The crystallographic refinement converged to an $R$-factor of $19 \%$ for 23,703 observed intensities $(F>2 \sigma(F))$ to a $3-\AA$ resolution. The present model consists of 1130 amino acid residues and does not include solvent molecules. The r.m.s. deviations from ideal bond lengths and angles are, respectively, $0.01 \AA$ and $1.65^{\circ}$. The electron density of the protein backbone is clearly defined for the two independent complexes and unambiguous for all the CDRs in contact with lysozyme (Fig. 1a). The refined coordinates have been deposited with the Protein Data Bank, Brookhaven, NY (Bernstein et al., 1977), code 1FBI.

Nucleotide and Protein Sequences of F9.13.7-Total mRNA was purified from $2 \times 10^{6}$ hybridoma cells by the method of acid guanidium thiocyanate extraction (Chomczynski and Sacchi, 1987). cDNA was produced from $5 \mathrm{mg}$ of total RNA using Superscript Reverse Transcriptase (Life Technolgies, Inc.) and $25 \mathrm{pmol}$ of immunoglobulin $\mathrm{H}$ or L chain constant region specific primers (Huse and Lerner, 1989). The cDNA was amplified by polymerase chain reaction using the same $3^{\prime}$ primer and a combination of eight 5' primers described by Huse and Lerner (1989), and the amplified products were cloned into polymerase chain reaction II plasmids (Invitrogen). Nucleotide sequencing was performed by the dideoxy chain termination method (Sequenase Sequencing kit, U. S. Biochemical Corp.). Sequencing was performed in 
both directions and confirmed by comparison of at least two clones obtained from separate polymerase chain reactions. The nucleotide sequences of the variable regions of the $\mathrm{H}$ and $\mathrm{L}$ chains have been deposited with GenBank (accession numbers U20819 and U20820).

Sequencing of the first nine amino acids from the $\mathrm{L}$ chain was carried out by Edman degradation on a 470 Applied Biosystems sequencer. No sequence data could be obtained for the $\mathrm{H}$ chain presumably due to a blocked amino terminus. Sequences were analyzed using GCG software (Devereux, 1991). Numbering of the amino acid positions follows the convention of Kabat et al. (1991).

Modeling-Electrostatic energy calculations were carried out as described by Pellegrini and Doniach (1993). A native-like conformation (within $3 \AA$, r.m.s.) was found to have the lowest electrostatic energy among several thousand conformations sampled during the docking search for the F9.13.7.GEL and HyHEL10-HEL complexes. The models of the chimeric low affinity complexes HyHEL10.JQL and F9.13.7.PHL were built by superimposing the crystallographic coordinates of the unliganded lysozyme (JQL, Houdusse (1992); PHL, Lescar et al. (1994)) on the crystal structures of the complex. In all cases, a short relaxation stage (to avoid significant departure from experimental coordinates) was followed by a molecular dynamics simulation carried out at $300 \mathrm{~K}$ for $100 \mathrm{fs}$, extracting the binding energy per residue every $10 \mathrm{fs}$.

Molecular surface areas were calculated using a modified version of the program MS (Connolly, 1983) with a probe radius of $1.7 \AA$ and standard Van der Waals' radii for protein atoms. The atomic coordinates of the HyHEL10.HEL complex were taken from the Protein Data Bank, code 3HFM.

\section{RESULTS}

The Overall Structure-The quaternary structure of the F9.13.7-GEL complex resembles that of other lysozyme-Fab complexes. mAb F9.13.7 binds lysozyme through a large contact surface formed by the CDRs at the amino-terminal end of the variable domain (see Fig. 5a). The two independent copies of the complex display systematic variations in overall temperature factors arising from a different packing environment (Lescar et al., 1993). Their backbone structures, however, are closely similar. The overall r.m.s. deviation between all 552 equivalent $\mathrm{C} \alpha$ coordinates is $0.99 \AA(0.62 \AA$ excluding the constant $\left(\mathrm{C}_{\mathrm{H}} 1+\mathrm{C}_{\mathrm{L}}\right)$ region). The two Fabs present the same extended conformation with an elbow bend between the variable and constant domains of $175^{\circ}$ in both complexes.

Complex formation induced only small conformational changes in the antigen polypeptide chain. Comparison of uncomplexed GEL determined at a 1.9- $\AA$ resolution (Lescar et al., 1994) with bound GEL gives r.m.s. deviations of 0.80 and 0.86 $\AA$ for corresponding main chain atoms, comparable with the differences observed between the two copies of lysozyme in the crystal structure of the complex $(0.87 \AA)$. The largest deviations (>1.4 $\AA$ ) occur for a lysozyme loop (positions 100-104) at the periphery of the epitope. This loop, however, has no clear conformation in the structure of uncomplexed GEL (Lescar et al., 1994), and the observed differences likely reflect its intrinsic flexibility.

The Lysozyme-Fab Interface-Antigen-antibody contacts are extensive and involve many residues. The epitope is discontinuous, consisting of 13 exposed residues from a central $\alpha$-helix (positions 88-99) and three surrounding loops (residues 15-21, $73-77$, and 100-103). The area of lysozyme that is in contact with the antibody is $760 \AA^{2}$. Twelve residues from the $\mathrm{H}$ chain and four from the L chain contribute to the binding of lysozyme (see Fig. $5 a$ ). This asymmetry is reflected by the buried surface areas upon complex formation $\left(570 \AA^{2}\right.$ for the $\mathrm{H}$ chain and 200 $\AA^{2}$ for the L chain). Indeed, only two lysozyme residues (Arg-73, Asn-77) interact with the L1 and L3 hypervariable loops, whereas all other lysozyme residues contact residues from the $\mathrm{H}$ chain (see Fig. 6a). A large number of electrostatic interactions are observed at the interface. Three salt bridges and 12 hydrogen bonds are formed between antibody and lysozyme residues (Table $I$ ). The majority of these polar contacts involve antibody residues from the $\mathrm{H} 2$ and $\mathrm{H} 3$ hypervariable regions.
TABLE I

Intermolecular hydrogen bonding interactions

Interactions defined as hydrogen bonds have proton-donor distances between 2.8 and $3.4 \AA$

\begin{tabular}{|c|c|c|c|}
\hline Antibody & \multicolumn{3}{|c|}{ Lysozyme } \\
\hline \multicolumn{4}{|l|}{ L1 } \\
\hline L3 ${ }^{\text {Tyr-32 }}$ & $\mathrm{O}_{\pi}$ & Arg-73 & $\mathrm{N}_{\mathrm{H} 2}$ \\
\hline H2 ${ }^{\text {Tyr-92 }}$ & $\mathrm{O}$ & Arg-73 & $\mathrm{N}_{e}$ \\
\hline Glu-50 & $\mathrm{O}_{\varepsilon 1}$ & Lys-97 & $\mathrm{N}_{7}$ \\
\hline Asp-52 & $\mathrm{O}_{\delta 1}$ & Tyr-20 & $\mathrm{O}_{\tau_{1}}$ \\
\hline Asp-52 & $\mathrm{O}_{\delta 2}^{\circ 1}$ & Lys-96 & $\mathbf{N}_{7}$ \\
\hline Ser-53 & $\mathrm{O}_{\gamma}$ & Lys-96 & $\mathrm{N}_{\mathrm{Z}}$ \\
\hline Asp-54 & $\mathrm{O}_{\delta 1}^{\gamma}$ & Asn-93 & $\mathbf{N}_{\delta 2}$ \\
\hline Asp-54 & $\mathrm{O}_{82}^{01}$ & His-15 & $\mathbf{N}_{\delta 1}^{02}$ \\
\hline Asn-58 & $\mathrm{O}_{\delta 1}$ & Asn-77 & $\mathbf{N}_{\delta 2}$ \\
\hline \multicolumn{4}{|l|}{ H3 } \\
\hline Tyr-96 & $\mathrm{O}$ & Arg-21 & $\mathrm{N}_{\mathrm{H} 1}$ \\
\hline Thr-100 & $\mathrm{O}_{\gamma 1}$ & Lys-97 & $\mathrm{O}$ \\
\hline Thr-100 & $\mathrm{N}^{\gamma 1}$ & Ser-100 & $\mathrm{O}$ \\
\hline Ser-100A & $\mathrm{O}$ & Arg-73 & $\mathbf{N}_{\mathbf{H} 1}$ \\
\hline Ser-100A & $\mathrm{O}_{\gamma}$ & Asp-101 & $\mathrm{O}_{\delta 1}$ \\
\hline Ser-100A & $\mathrm{N}^{y}$ & Asp-101 & $\mathrm{O}_{\delta 1}$ \\
\hline
\end{tabular}

Somatic Mutations-The antibody F9.13.7 expresses a member of the $\mathrm{V}_{\mathrm{H}} 124$ variable, DFL16.1 diversity, and $\mathrm{J}_{\mathrm{H}^{4}}$ joining gene segment families in the $\mathrm{H}$ chain and $\mathrm{V} \kappa 10$-Ars-A and $\mathrm{J}_{\kappa 2}$ in the $\mathrm{L}$ chain. Comparison with the germline sequences (Fig. 2) suggests that somatic mutations make a limited contribution to binding affinity. Five nucleotide differences are observed in each of the two variable segments. Four of these (at positions L23, L68, H50, and H63) are silent mutations, and three others (L38, L76, and H40) involve framework residues that do not contact the antigen. Two expressed mutations occurring in the H2 loop, Thr(H58) $\rightarrow$ Pro and $\mathrm{Gln}(\mathrm{H} 62) \rightarrow$ Glu, affect positions that are not in contact with lysozyme. Furthermore, these substitutions do not affect the conformation of the loop compared with that of D11.15, another anti-lysozyme antibody that has the germline-encoded amino acids at these positions (Fig. 3 ). Indeed, the only change of somatic origin affecting a residue contacting lysozyme involves L chain Tyr(L92) (Asn in the $\mathrm{V} \kappa 10$-Ars-A sequence), partially stacked against the $\delta$-guanido group of Arg-73 (see Fig. 8a).

Conformation of the Complementarity-determining Regions-The $\mathrm{L}$ chain of $\mathrm{F9} .13 .7$ is very similar to that of $\mathrm{CRI}_{\mathrm{A}^{-}}$ positive anti-p-azobenzenearsonate antibodies (Sanz and Capra, 1987). The amino acid sequences of $V_{L}$ F9.13.7 and the anti-arsonate R19.9 (Lascombe et al., 1992) differ at only five positions (Fig. 2), and the corresponding $\mathrm{C} \alpha$ coordinates can be superimposed with a r.m.s. deviation of $0.58 \AA$. In particular, the three hypervariable loops have the same conformation with only two amino acid substitutions in the L3 loop, reinforcing the concept that their $\mathrm{H}$ chain partners are the primary determinants of specificity (Siekevitz et al., 1983).

The $\mathrm{V}_{\mathrm{H}}$ domain of F9.13.7 resembles that of anti-HEL antibody D11.15 (Chitarra et al., 1993). The H1 and H2 loops of these two antibodies are closely similar, although they contribute significantly ( $50 \%$ of the corresponding contact surfaces) to binding nonoverlapping regions of lysozyme (Fig. 3). This comparison illustrates how the same structural elements can confer binding specificity in quite different stereochemical environments. This lends further support to the canonical loop hypothesis (Chothia et al., 1989), according to which a limited set of hypervariable loop conformations is sufficient to generate diversity.

The long H3 loop (13 residues), which has the same conformation in the two noncrystallographically related complex molecules, partially protrudes into the active site cleft of lysozyme. 
a

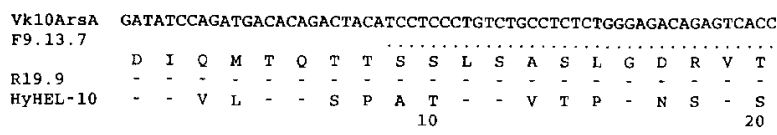

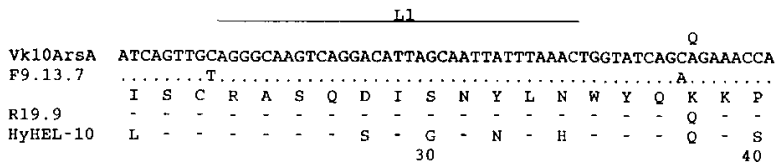
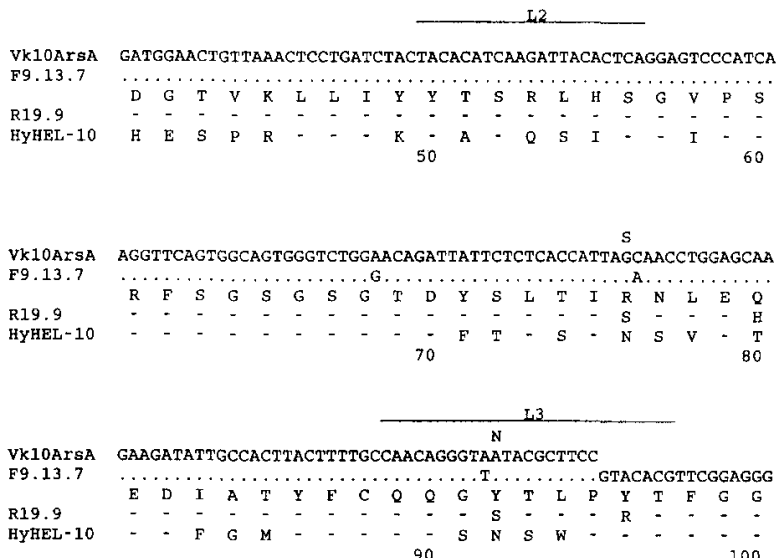

$\begin{array}{lllllllll}\text { F9.13.7 GGGACCAAGCTGGAAATAAACGG } \\ & \text { G } & \text { T } & \text { K } & \text { L } & \text { E } & \text { I } & \text { K } & \text { R } \\ \text { R19.9 } & - & - & - & - & - & - & - & - \\ \text { HYHEL-10 } & - & - & - & - & - & - & - & -\end{array}$

b

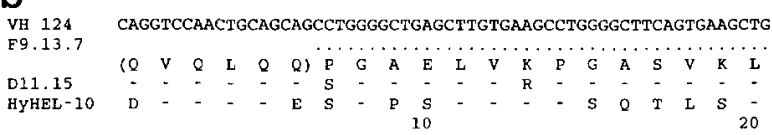

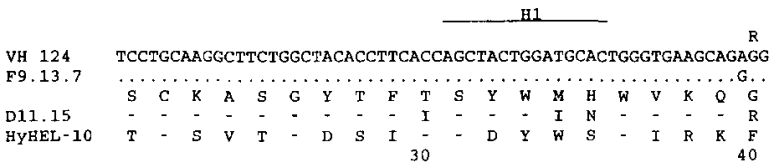

VH 124 CCTGGACAAGGCCTTGAGTGGATCGGAGAGATTGATCCTTCTGATAGTTATACTAACTAC

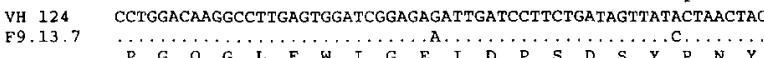

$\begin{array}{lllllllllllllllllllll} & \text { P } & G & Q & G & \text { L } & \text { E } & \text { W } & \text { I } & \text { G } & \text { E } & \text { I } & \text { D } & \text { P } & \text { S } & \text { D } & \text { S } & \text { Y } & \text { P } & \text { N } & \text { Y } \\ \text { HYHEL } 15 & - & - & - & - & - & - & - & - & - & \text { N } & - & \text { Y } & - & - & - & - & - & T & - & - \\ \text { HY } & - & - & \text { N } & \text { R } & - & - & \text { Y } & \text { M } & - & \text { Y } & \text { V } & \text { S } & & \text { Y } & \text { S } & \text { G } & \text { S } & \text { T } & \text { Y } & -\end{array}$

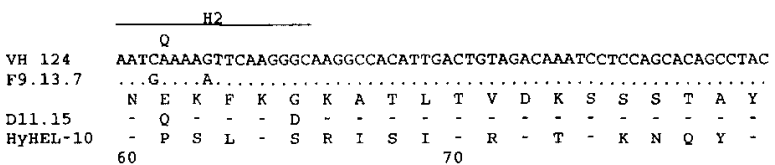

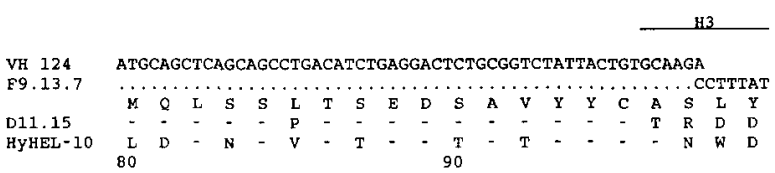

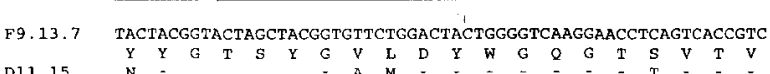
D11.15

100

FIG. 2. Nucleotide and deduced amino acid sequence of the $V_{\kappa}$ (a) and $V_{H}$ (b) domains of F9.13.7. The nucleotide sequences are
Three consecutive Tyr residues encoded by the diversity gene segment are involved in stacking interactions with aromatic residues from neighboring CDRs (Fig. $1 b$ ); the next four residues, at the tip of $\mathrm{H} 3$, form a $310^{\text {-helical turn that makes }}$ contact with lysozyme residues (in particular with Trp-63 on the enzyme active site), and the subsequent three amino acids adopt an extended conformation that connects back with the framework $\beta$-strand.

Comparison of F9.13.7-GEL and HyHEL10-HEL Complexes-The epitope of GEL defined by F9.13.7 extensively overlaps with that of the antibody HyHEL10 (Padlan et al., 1989). The same 12 residues of the antigen (see Fig. 6) make 14 of the 15 intermolecular hydrogen bonds or salt links observed in each complex (Table I). The surface areas buried upon Fablysozyme interaction are about the same for the two complexes ( $770 \AA^{2}$ for the antibody and $760 \AA^{2}$ for lysozyme). The overlap between the lysozyme epitopes bound by mAbs F9.13.7 and HyHEL10 can be numerically evaluated by plotting the surface lost by each lysozyme residue upon complex formation (Fig. 4).

Despite binding a nearly identical epitope, the two antibodies have no sequence similarity at any of their CDRs (Fig. 2) and bind the epitope in different relative orientations (Fig. 5). A topographic correspondence can be established between the hypervariable loops L3 of F9.13.7 and H1 of HyHEL10, both of which interact with the same region of lysozyme (Fig. 6). In addition, the H3 loop of F9.13.7 fulfills an analogous role to that of $\mathrm{H} 2$ in HyHEL10, creating a protrusion that partially fits into the active site cleft of lysozyme (Figs. $1 b$ and 5). On the opposite side of the epitope, H1 (F9.13.7) substitutes for L3 (HyHEL10), and extensive contacts made by the $\mathrm{H} 2$ region of F9.13.7 are made by L1 and L2 in the HyHEL10.HEL complex. The unusually short H3 loop of HyHEL10 contributes a single residue (Trp(H95)) to binding, as does the L1 loop of F9.13.7 (Tyr(L32)).

Several intermolecular hydrogen bonds and salt bridges are observed in the two antigen-antibody interfaces. In general, the polar and charged groups are distributed in a similar fashion at the two antibody combining sites, clustered on a ridge approximately $10 \AA$ from the geometric center of the antigen-binding region. Essentially the same epitope residues (which are identical between GEL and HEL) are involved in polar interactions with the antibody combining sites. A single salt bridge between Asp(H32) from the $\mathrm{H}$ chain and Lys-97 from lysozyme was found in the HyHEL10.HEL complex, despite the presence of several exposed charged residues (Padlan et al., 1989). The situation is different for F9.13.7, since the H2 loop contains two germline-encoded Asp and one Glu that form ion pairs with basic residues of the epitope (Fig. 6a). Thus, Asp(H52) interacts with Lys-96, Asp(H54) with His-15, and Glu(H50) with Lys-97. The (Asp(H54)-His-15) salt bridge, however, is exposed to the solvent and could be weakened by hydration.

The overall backbone structures of GEL bound to F9.13.7 and HEL bound to HyHEL10 are very similar despite the sequence differences between HEL and GEL (r.m.s. deviation of $0.89 \AA$ for equivalent $\mathrm{C} \alpha$ positions), indicating that heterologous binding can be achieved with little conformational change in the lysozyme backbone. Complex formation, how-

compared with those of the germline segments $\mathrm{V}_{\kappa} 10-\mathrm{Ars}-\mathrm{A}$ and $\mathrm{V}_{\mathrm{H}} 124$ Germline-encoded amino acids that differ from those of F9.13.7 are indicated above the nucleotide sequence. The protein sequence of the $V_{\kappa}$ domain of F9.13.7 is compared with those of anti-arsonate antibody R19.9 and HyHEL10. The protein sequence of the $V_{H}$ domain of F9.13.7 is compared with those of anti-lysozyme antibodies D11.15 and HyHEL10. Dots indicate nucleotide identities; dashes indicate amino acid identities. Numbering is as in Kabat et al. (1991). The nucleotides corresponding to the first six amino acids of the $V_{H}$ domain of F9.13.7 have not been sequenced. 


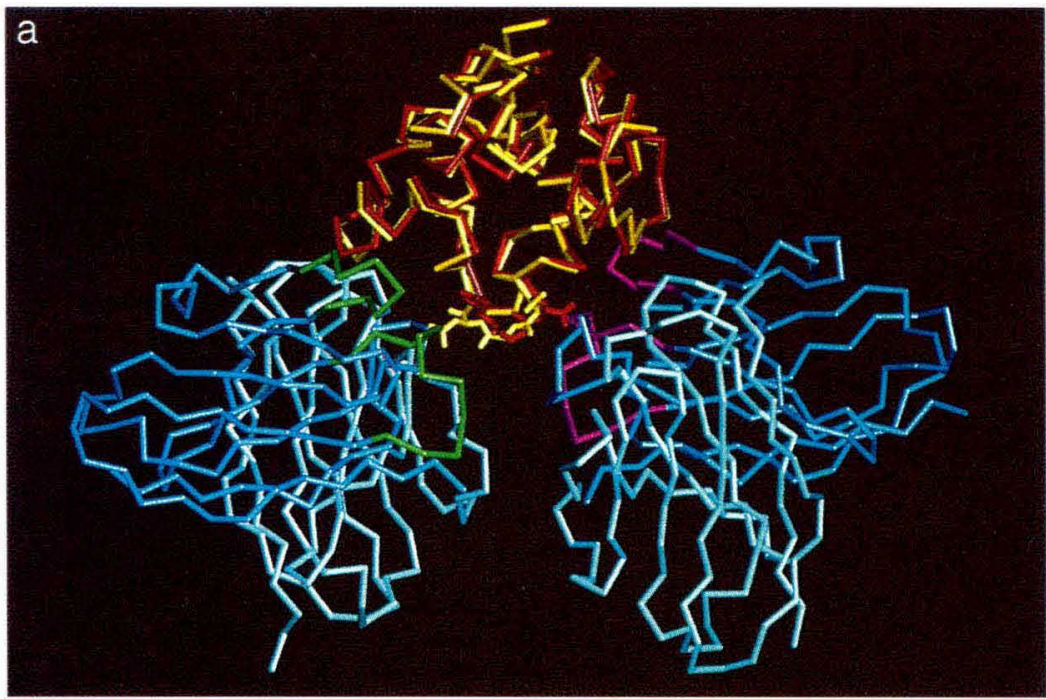

FIG. 3. $\alpha, \alpha$-carbon trace of the variable regions of D11.15 (left) bound to PHL (in red) and of F9.13.7 (right) bound to GEL (in yellow). The hypervariable loops $\mathrm{H} 1$ and H2 of D11.15 (in green) and of F9.13.7 (in purple) contact different regions of the lysozyme surface. Side chain atoms are shown for the lysozyme loop at positions 100-103. b, main chain atoms of the superimposed $\mathrm{H} 1$ and $\mathrm{H} 2$ loops are colorcoded as above.

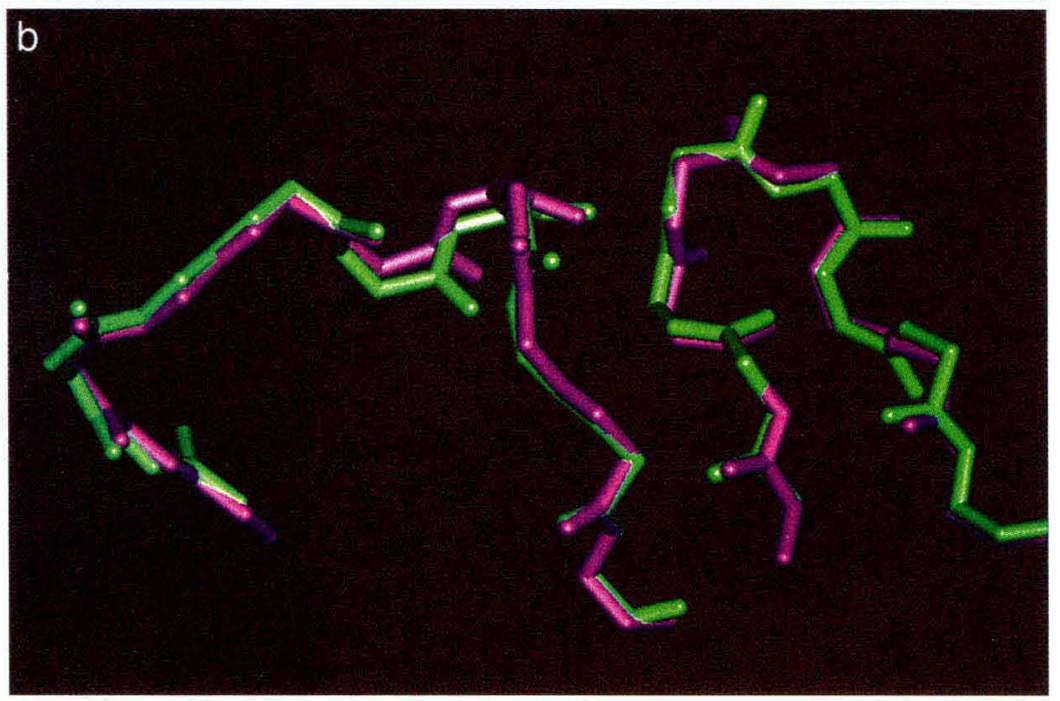

ever, entails more significant differences in side chain conformations. The equivalent $\mathrm{C} \alpha$ atoms of the 12 lysozyme residues common to both epitopes can be superimposed with r.m.s. deviations of $0.8-0.9 \AA$, but these values rise to $1.5-1.6 \AA$ when main chain and side chain atoms are included in the comparisons. The flexibility of side chains permits surface variations on lysozyme that match steric differences between the two antibody combining sites and allows for complementarity of the antigen-antibody interfaces.

Fine Specificity of F9.13.7-The association constant of F9.13.7 for HEL, as determined by microcalorimetric techniques, is $3.4 \times 10^{8} \mathrm{M}^{-1}$ (Tello et al., 1993). Cross-reactions of F9.13.7 with other avian lysozymes indicated that the relative affinity for GEL, bobwhite quail, and California quail lysozymes were similar to that for HEL, whereas much weaker or no reactions were observed for JQL, PHL, and turkey lysozymes (Tello et al., 1990).

The reduced affinity of antibodies F9.13.7 and D11.15 for JQL, which has two amino acid substitutions at positions 102 and 103 compared with HEL, has led to the assumption that this region could be bound by the two antibodies and that their epitopes could overlap. This hypothesis, however, is inconsistent with the formation of a ternary complex F9.13.7.HEL·D11.15, observed by gel filtration chromatography (data not shown). In the crystal structures of the Fab D11.15.PHL (Chitarra et al., 1993) and the Fab F9.13.7.GEL complexes, residues from the lysozyme loop 100-103 interact with the two antibody combining sites, in agreement with the immunochemical mapping results. Nevertheless, simultaneous binding by the two antibodies is possible (Fig. 3) with only a minor conformational adjustment of the loop backbone needed to avoid steric clash.

Cross-reactivity Pattern of F9.13.7 and HyHEL10-Despite binding a common set of residues, the F9.13.7 and HyHEL10 antibodies display a different pattern of fine specificity toward heterologous lysozymes. Both antibodies bind HEL and GEL with comparable affinities, but react differently with JQL and PHL. The F9.13.7.JQL and HyHEL10.PHL complexes have similar high affinities, whereas the association constant of the F9.13.7.PHL and HyHEL10.JQL complexes is significantly weaker (Smith-Gill et al., 1984; Tello et al., 1990). Thus, epitope mapping based on binding assays would point to different antigenic determinants (functional epitopes) on lysozyme, although the two antibodies recognize a very similar structural region, illustrating how different analytical approaches may lead to different perceptions of a protein epitope (Van Regenmortel, 1989).

Electrostatic model calculations carried out for the F9.13.7.GEL and HyHEL10.HEL complexes suggest that a few lysozyme residues, different for each antibody, contribute the most to binding. In the HyHEL10.HEL complex, three residues of the epitope (Arg-21, Lys-97, and Asp-101) account for half of the total average binding energy, in agreement with mutagenesis studies (Kam-Morgan et al., 1993), showing that substitu- 


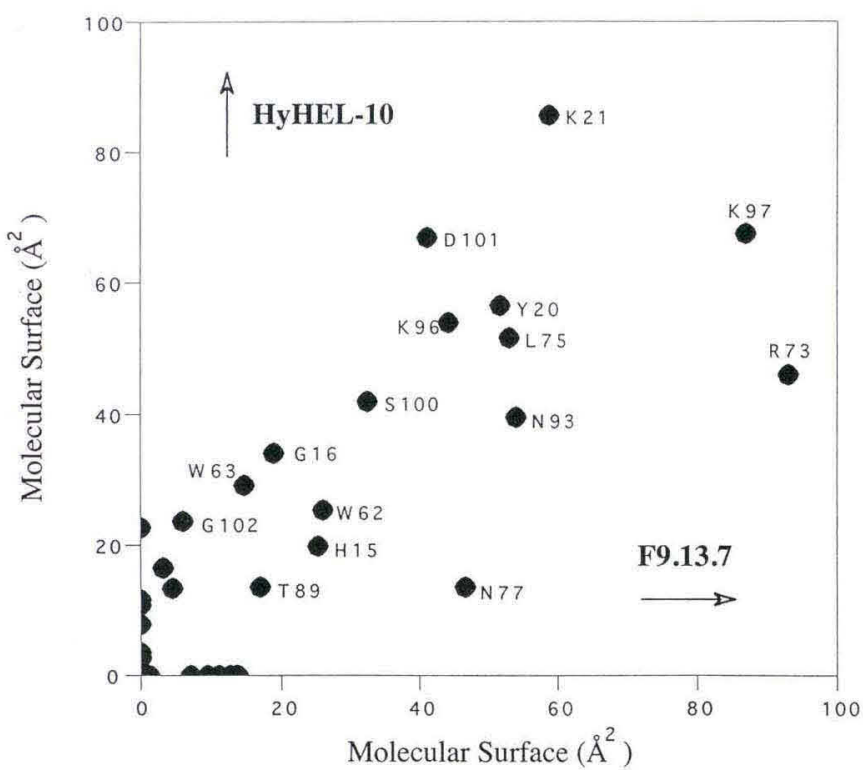

FIG. 4. Buried surface areas of lysozyme residues contacting the F9.13.7 and HyHEL10 antibodies upon formation of the complex. The overall correlation is $61 \%$.

tions of Arg-21 or Asp-101 significantly decrease the binding constant for HyHEL10. On the other hand, five residues (His15, Arg-73, Lys-96, Lys-97, and Asp-101) contribute $80 \%$ of the F9.13.7-GEL binding energy. Leaving aside the expected contribution of amino acids involved in intermolecular salt bridges (His-15, Lys-96, and Lys-97), these results suggest that the arginine residues at positions 21 and 73 are important in accounting for the difference in antibody specificity.

The side chain of Arg-73 protrudes toward the antibody combining site in both structures. In the F9.13.7 GEL complex, it is mostly occluded from the solvent by stacking interactions with Tyr(L92), which, together with Tyr(L32) and Leu(L94), form a ridge on the antibody surface (Fig. $7 a$ ). In contrast, the same arginine is largely exposed to the solvent in the HyHEL10.HEL interface (Fig. $7 b$ ). Furthermore, the planar ring of active site residue Trp-62 is oriented differently in the two bound lysozymes: perpendicular to the interface in the F9.13.7-GEL complex (where it is stacked against the Arg-73 side chain) and roughly parallel to the interface (and to the aromatic ring of $\operatorname{Tyr}(\mathrm{H} 53)$ ) in the HyHEL10.HEL complex. The structural environment of Arg-73 is therefore consistent with the different binding constants of the antibodies for PHL and turkey lysozyme, for which two amino acid changes occur at the epitope with respect to HEL (His-15 $\rightarrow$ Met/Leu) and (Arg-73 $\rightarrow$ Lys).

On the opposite side of the epitope, Arg-21 binds to a pocket formed by the H2 and L3 loops of HyHEL10 (Fig. 8b). The $\delta$-guanido group of the arginine side chain is within hydrogen bonding distance of Tyr(H50), whereas its aliphatic moiety is partially screened from the solvent by the planar rings of Trp(L94) and Tyr(H58). The F9.13.7 combining site lacks a similar binding pocket; the Arg-21 side chain is in contact with the aromatic ring of $\operatorname{Tyr}(\mathrm{H} 32)$ but otherwise exposed to the solvent (Fig. 8a). The structural context around Arg-21 could account for the weak reaction of HyHEL10 with JQL, which has a glutamic acid at this position (Kam-Morgan et al., 1993). The same substitution would instead have a limited effect on F9.13.7 reactivity because of a stereochemically permissive environment. Two additional amino acid differences between HEL and JQL at positions close to the antigen-antibody interface, Gly-102 (HEL) $\rightarrow$ His (JQL) and Asn-103 (HEL) $\rightarrow$ His (JQL), appear to be less critical for binding, since replacements
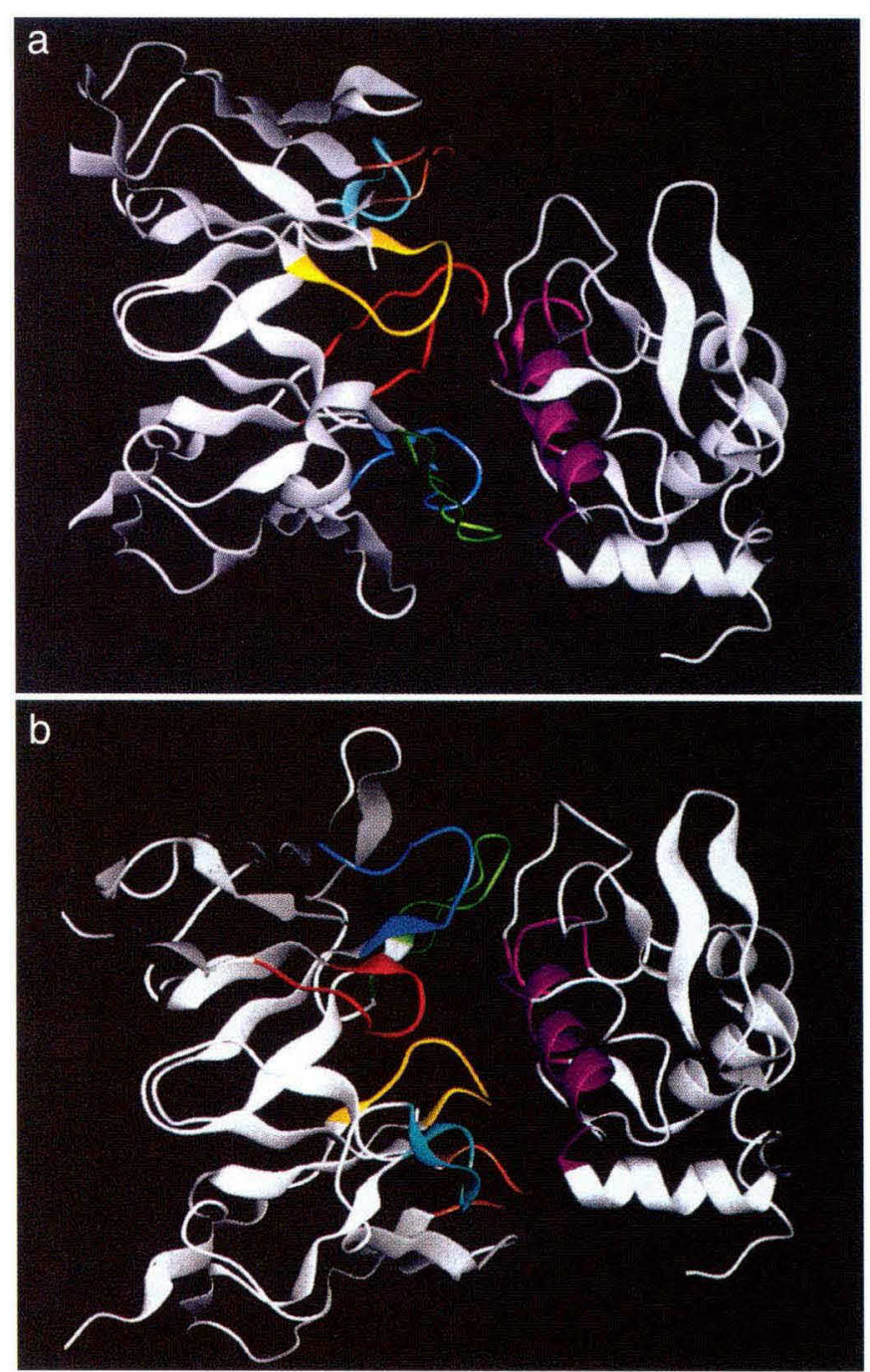

FIG. 5. Overall view of the F9.13.7-GEL ( $a$ ) and HyHEL10-HEL (b) complexes with the antigens in similar orientations. Only the variable dimers have been represented for clarity. The color scheme of the backbone representation is as follows: lysozyme epitope, purple; L1, brown; L2, light blue; L3, yellow; H1, dark blue; H2, green; H3, red.

of Gly-102 have no effect on the affinity of HEL for HyHEL10 (Kam-Morgan et al., 1993).

\section{DISCUSSION}

The F9.13.7-GEL complex shares common features with other antibody-antigen complexes whose structures have been reported. The molecular surfaces brought in contact upon complex formation are of comparable size, largely complementary in shape, and involve a similar number of contact residues and hydrogen bonds. The equilibrium association constant $\left(K_{a}=\right.$ $10^{8} \mathrm{M}^{-1}$ ) is also typical of previously studied antigen-antibody complexes $\left(K_{\alpha}=10^{7}-10^{10} \mathrm{M}^{-1}\right)$.

Comparative studies of known antibody structures have led Chothia and Lesk (1987) to propose the existence of a small number of backbone conformations, or canonical structures, for five of the six hypervariable loops. The results presented in this paper further substantiate this hypothesis. Although the homologous $\mathrm{H} 1$ and H2 hypervariable loops of F9.13.7 and D11.15 have very similar conformations (Fig. 3b), they account for about half of the corresponding combining site surfaces and are engaged in interactions with quite different structural environments. This finding has interesting implications, not only for the modeling of antibody combining sites (Chothia et al., 1989) but also for the molecular mechanisms that generate antibody 

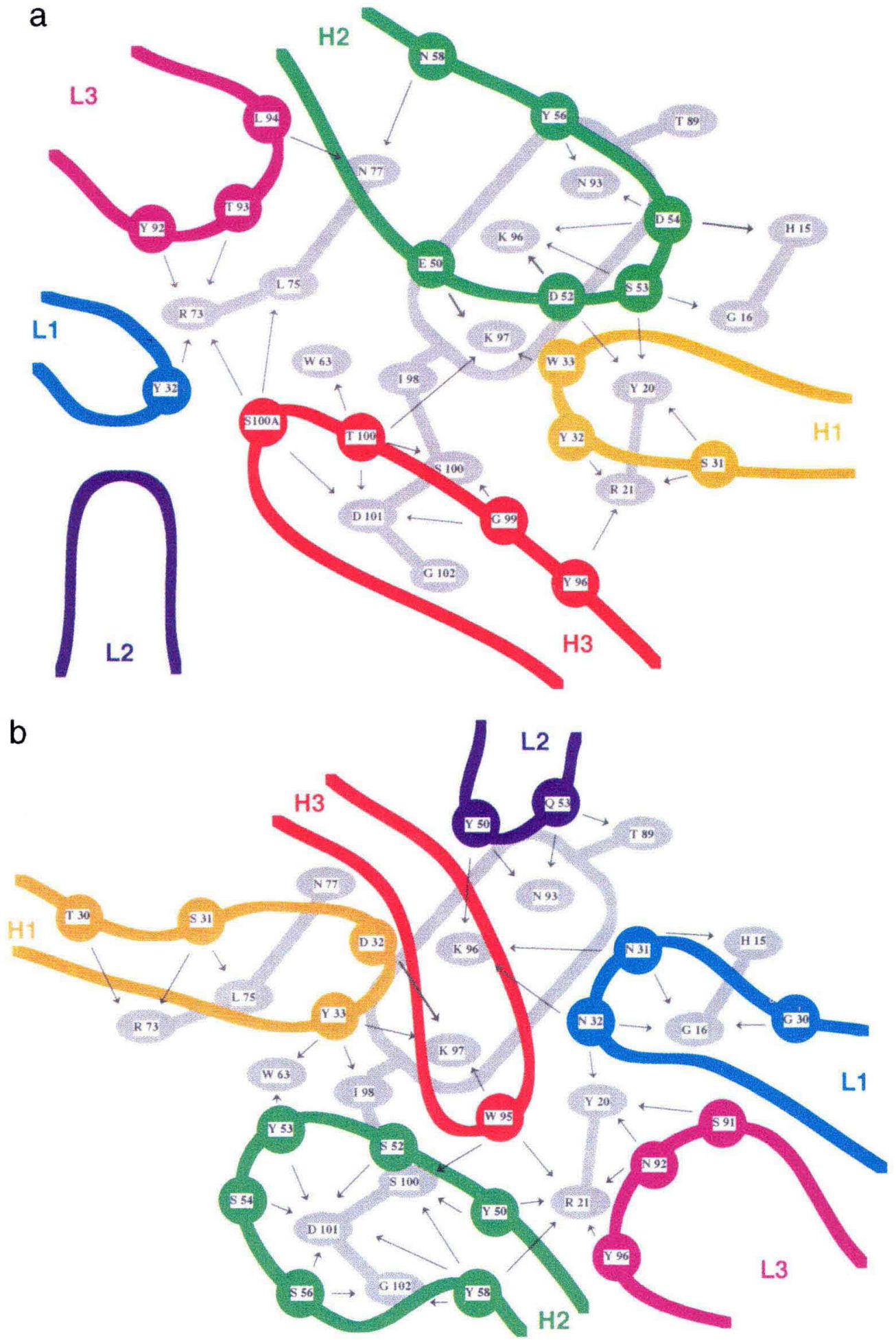

FIG. 6. Schematic view of the intermolecular contacts $(<4 \AA)$ showing the relative disposition of the CDRs with respect to the epitope for the F9.13.7-GEL $(a)$ and HyHEL10-HEL $(b)$ complexes. Antigen is represented in gray (a rounded rectangle represents the lysozyme $\alpha$-helix) and antibody in color. Intermolecular salt linkages are indicated with thick arrows.

diversity, since a limited set of main chain conformations for most hypervariable loops would ensure a potentially unlimited functional repertoire.

Further evidence of heterologous binding is provided by the comparison of the F9.13.7-GEL and HyHEL10.HEL complexes. 12 out of 13 lysozyme residues in contact with the F9.13.7 combining site also interact with that of HyHEL10, despite the absence of amino acid sequence homology in the CDRs of the two antibodies. Other examples of unrelated proteins binding a same set of amino acid residues have been reported. Bentley et al. (1990) found that seven amino acid residues of anti-HEL antibody D1.3 are involved in interactions with both the antigen and an anti-idiotypic antibody, whereas the structure of the complex between the monomeric human growth hormone and its dimeric receptor (de Vos et al., 1992) showed that the same set of residues on the two receptor monomers binds a different structure on the hormone. More recently, Malby et al. (1994) found that approximately $80 \%$ of the binding site of 
a

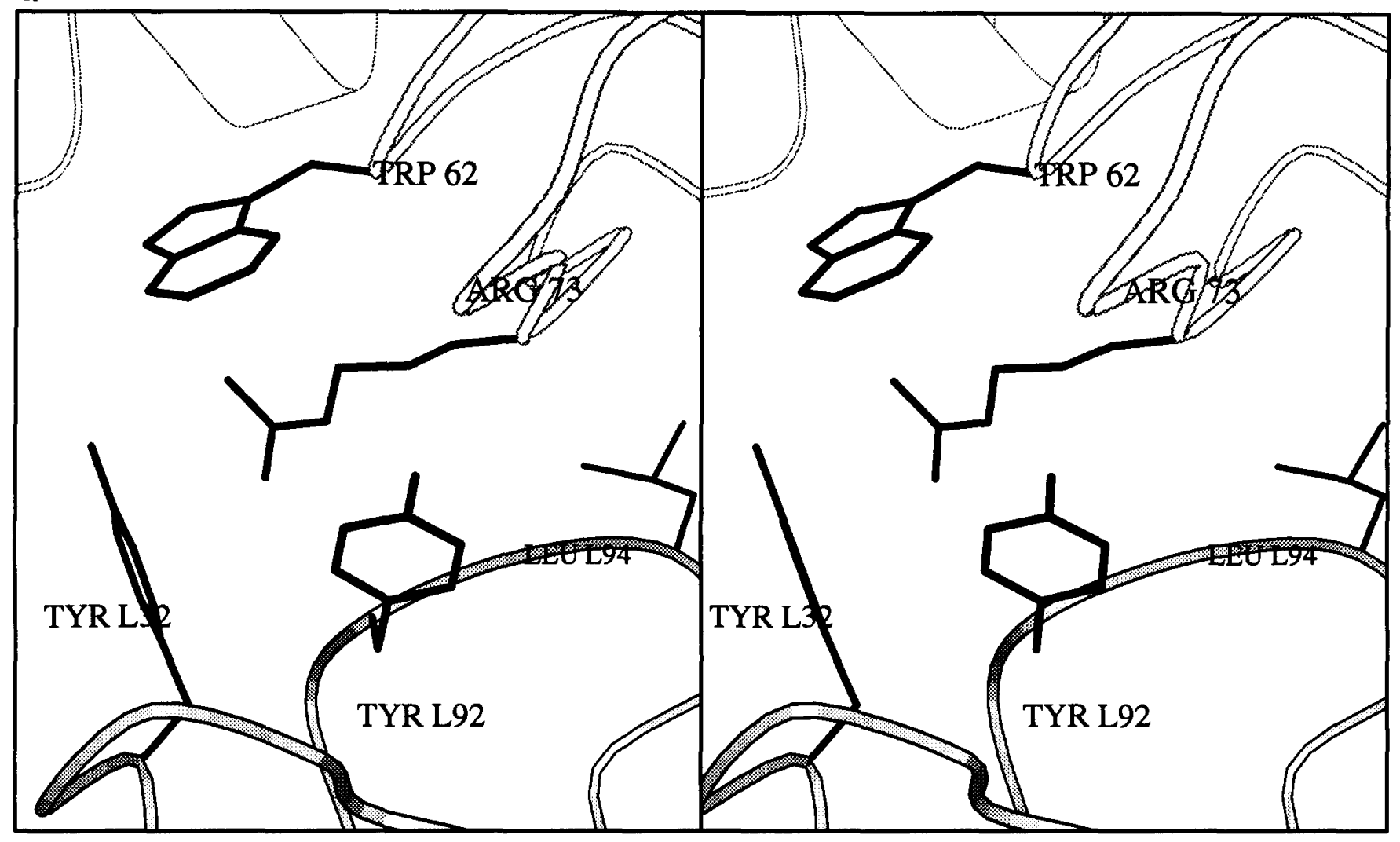

b

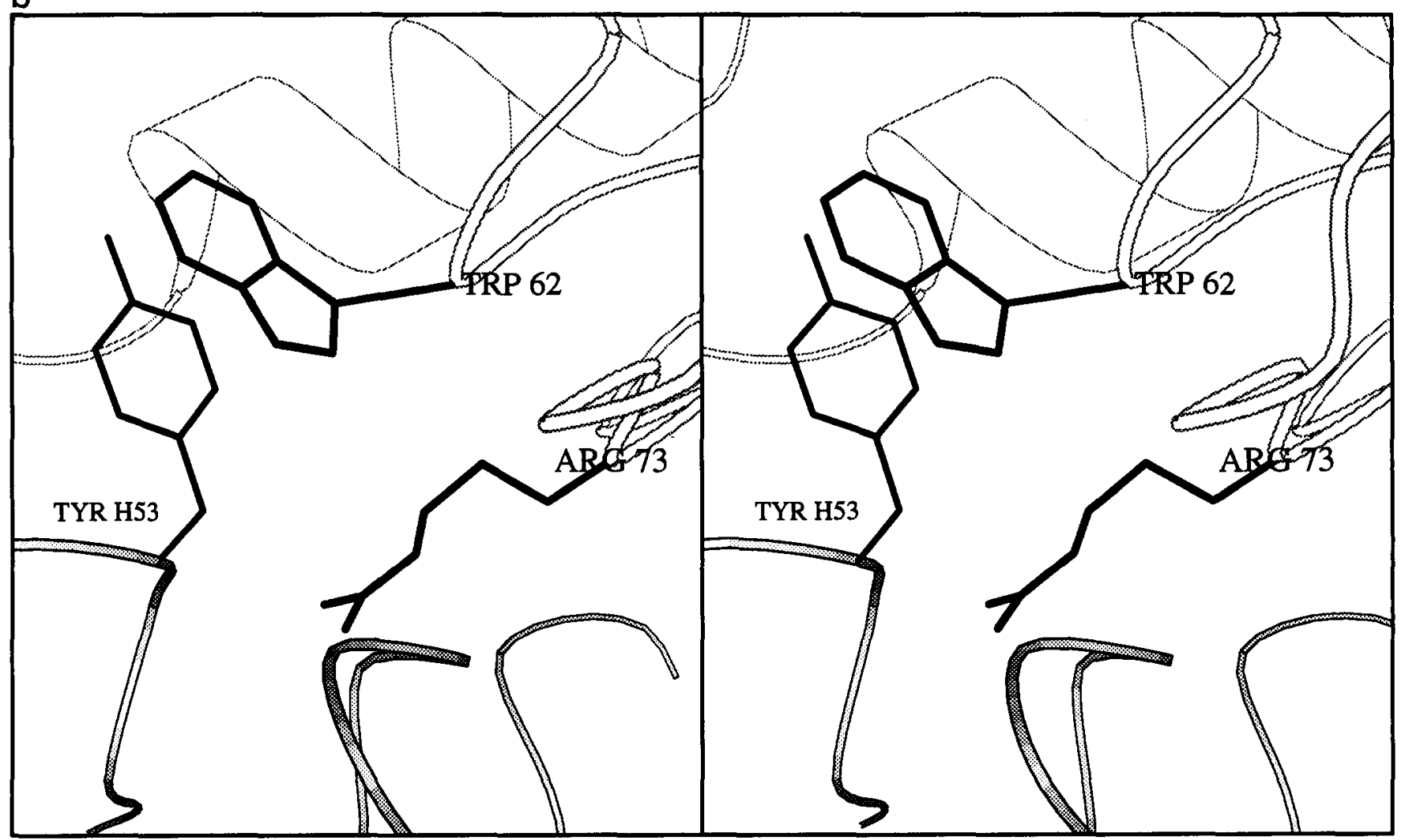

FIG. 7. Stereo view of the structural environment around Arg-73 in the F9.13.7-GEL (a) and HyHEL-10-HEL (b) complexes. Lysozyme backbone is shown in white; antibody backbone is shown in gray (see text for details). 

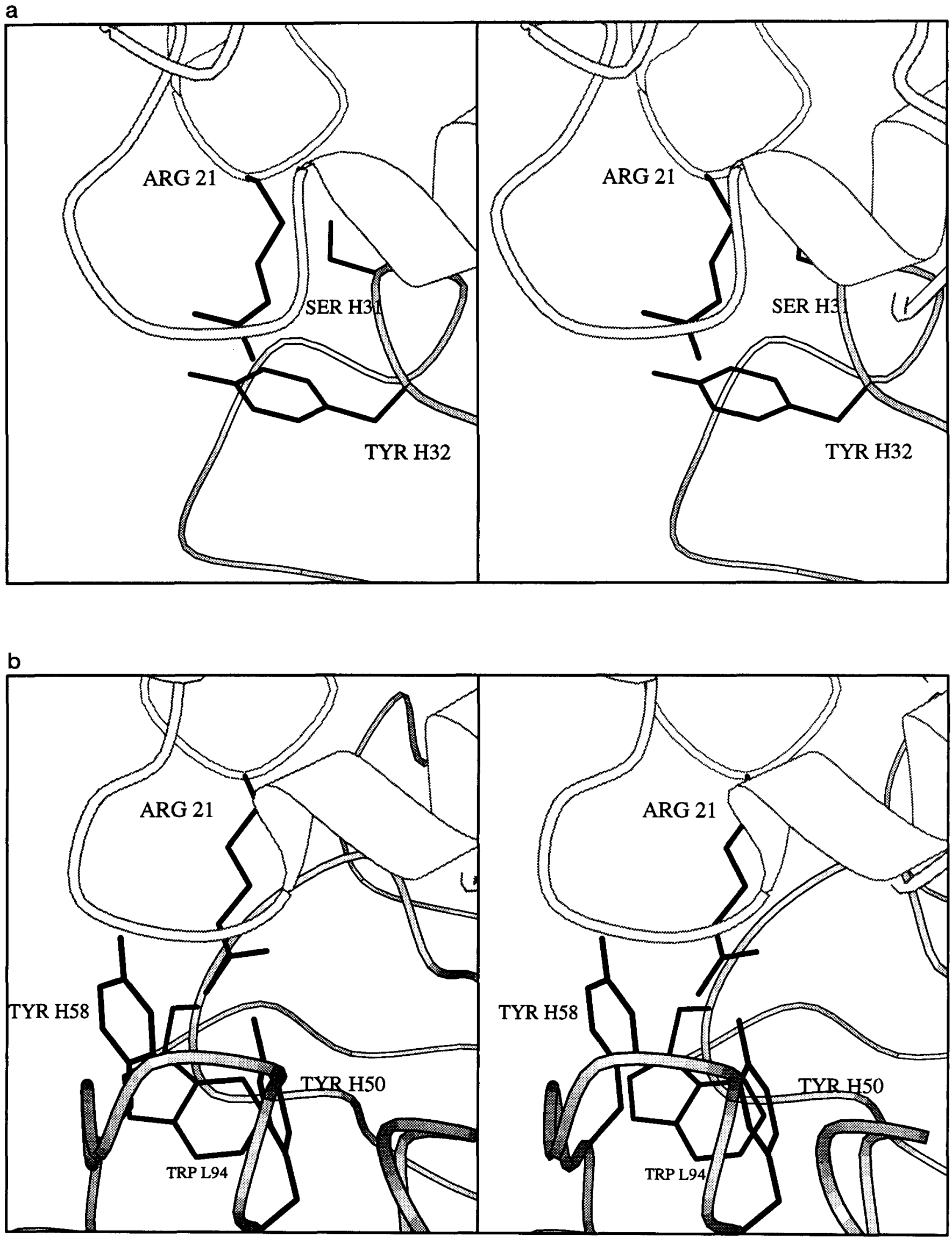

FIG. 8. Stereo view of the region around Arg-21 in the F9.13.7-GEL (a) and HyHEL-10-HEL (b) complexes. 
NC10 antibody on neuraminidase overlaps with that of the NC41 antibody and Braden et al. (1994) showed that mAbs D44.1 and HyHEL-5 bind a nearly identical epitope on lysozyme (in this case the $\mathrm{H}$ chains of the two mAbs result from the expression of the same $\mathrm{V}_{\mathbf{H}}$ gene although their $\mathrm{H} 3$ regions and $L$ chains are unrelated, giving different combining sites and interactions with lysozyme). In none of these examples do cross-reacting molecular surfaces display obvious structural similarity.

Previous studies of anti-idiotypic antibodies have suggested that in certain cases functional mimicry could be partially based on a true molecular mimicry (for review, see Taub and Greene (1992) and Mariuzza and Poljak (1993)), the most plausible example being provided by a crystallographic study of anti-angiotensin II antibodies (Garcia et al., 1992). The data presented here demonstrate that functional mimicry by the two antibodies is possible even in the absence of any sequence similarity in their combining sites. Since antigen selection operates on functional, not structural, conformations, the known difficulties encountered in evidencing antibody mimics (see, for example, Davis et al. (1992)) suggest that heterologous binding by unrelated molecular surfaces may be a common phenomenon in antigen-antibody interactions. This is in agreement with the known degeneracy of immune responses and germline gene information to provide complementary structures that bind specifically to an antigenic determinant.

Comparison of the F9.13.7- and HyHEL10-bound lysozymes provides an estimate of the extent to which conformational changes are involved in producing the observed complementarity of the antigen-antibody interfaces. The plasticity of the epitope contributes to restore steric complementarity to differently shaped combining sites. Indeed, molecular surface adaptability appears to be a general principle underlying promiscuity in protein-protein interactions (Malby et al., 1994). In the case of lysozyme, these changes arise primarily from side chain mobility and are not significantly reflected at the backbone level. This example and other recent studies of antigen-antibody interactions (for review, see Davies and Padlan (1992) and Wilson and Stanfield (1993)) underline the role of conformational changes in immune recognition and may have important implications for theoretical approaches to modeling proteinprotein interactions.

Acknowledgments-We thank J. D'Alayer for protein sequencing and our collegues G. A. Bentley and F. A. Saul for help in data collection and stimulating discussions. We also thank the LURE staff for access to synchrotron beamline.

\section{REFERENCES}

Amit, A. G., Mariuzza, R. A., Phillips, S. E. V., and Poljak, R. J. (1986) Science 233, 747-753

Benjamin, D. C., Berzorsky, J. A., East, I. J., Gurd, F. R. N., Hannum, C., Leach, S. J., Margoliash, E., Michael, J. G., Miller, A., Prager, E. M., Reichlin, M., Sercarz, E. E., Smith-Gill, S. J., Todd, P. E., and Wilson, A. C. (1984) Annu. Rev. Immunol. 2, 67-101

Bentley, G. A., Boulot, G., Riottot, M.-M., and Poljak, R. J. (1990) Nature 348,
$254-257$

Bernstein, F. C., Koetzle, T. F., Williams, G. J. B., Meyer, E. F., Jr., Brice, M. D., Rodgers, J. R., Kennard, O., Simanouchi, T., and Tasumi, M. (1977) J. Mol. Biol. $112,535-542$

Braden, B. C., Souchon, H., Eisele, J.-L., Bentley, G. A., Bhat, T. N., Navaza, J., and Poljak, R. J. (1994) d. Mol. Biol. 243, 767-781

Bricogne, G. (1976) Acta Crystallogr. 32, 832-846

Brünger, A. T., Kuriyan, J., and Karplus, M. (1987) Science 235, 458-460

Chitarra, V., Alzari, P. M., Bentley, G. A., Bhat, T. N., Eiselé, J.-L., Houdusse, A Lescar, J., Souchon, H., and Poljak, R. J. (1993) Proc. Natl. Acad. Sci. U. S. A $90,7711-7715$

Chomezynski, P., and Sacchi, N. (1987) Anal. Biochem. 162, 156-159

Chothia, C., and Lesk, A. M. (1987) J. Mol. Biol. 196, 901-917

Chothia, C., Lesk, A. M. Tramontano, A., Levitt, M., Smith-Gill, S. J., Air, G., Sheriff, S., Padlan, E. A., Davies, D., Tulip, W. R., Colman, P. M., Spinelli, S. Alzari, P. M., and Poljak, R. J. (1989) Nature 342, 877-883

Connolly, M. L. (1983) J. Appl. Crystallogr. 16, 548-558

Davies, D. R., and Padlan, E. A. (1992) Curr. Opinion Struct. Biol. 2, 254-256

Davis, S., Schockmel, G., Somoza, C., Buck, D., Healey, D., Rieber, E., Reiter, C. and Williams, A. (1992) Nature 358, 76-79

de Vos, A., Ultsch, M., and Kossiakoff, A. A. (1992) Science 255, 306-312

Devereux, J. (1991) The GCG Sequence Analysis Software Package, Version 7.0 Genetics Computer Group, Inc., Madison WI 53711

Fischmann, T. O., Bentley, G. A., Bhat, T. N., Boulot, G., Mariuzza, R. A., Phillips, S. E. V., Tello, D., and Poljak, R. J. (1991) J. Biol. Chem. 266, 12915-12920

Garcia, K. C., Ronco, P. M., Verroust, P. J., Brünger, A. T., and Amzel, L. M. (1992) Science 257, 502-507

Harper, M., Lema, F., Boulot, G., and Poljak, R. J. (1987) Mol. Immunol. 24, 97-108

Houdusse, A. (1992) Structure d'un Anticorps Anti-idiotype. Ph.D. thesis, Université Paris-Sud, France

Huse, W., Sastry, D. L., Iverson, S. A., Kang, A. S., Alting-Mees, M., Barton, D. R. Benkovic, S. J., and Lerner, R. (1989) Science 246, 1275-1281

Jones, T. A. (1978) J. Appl. Crystallogr. 11, 268-272

Kabat, E. A., Wu, T. T., Perry, H. M., Gottesman, K. S., and Foeller, C. (1991) Sequences of Proteins of Immunological Interest. NIH Publication 91-3242. National Institutes of Health, Bethesda

Kam-Morgan, L. N. W., Smith-Gill, S. J., Taylor, M. G., Zhang, L., Wilson, A. C. and Kirsch, J. F. (1993) Proc. Natl. Acad. Sci. U. S. A. 90, 3958-3962

Lascombe, M.-B., Alzari, P. M., Poljak, R. J., and Nisonoff, A. (1992) Proc. Natl. Acad. Sci. U. S. A. 89, 9429-9433

Lavoie, T. B., Drohan, W. N., and Smith-Gill, S. J. (1992) J. Immunol. 148, $503-513$

Lescar, J., Riottot, M.-M., Souchon, H., Chitarra, V., Bentley, G. A., Navaza, J. Alzari, P. M., and Poljak, R. J. (1993) Proteins 15, 209-212

Lescar, J., Souchon, H., and Alzari, P. M. (1994) Protein Sci. 3, 788-798

Leslie, A. (1990) Crystallographic Computing, pp. 110-125, Oxford, UK, Oxford University Press,

Malby, R. L., Tulip, W. R., Harley, V. R., McKimm-Breschkin, J. L., Laver, W. G. Webster, R. G., and Colman, P. M. (1994) Structure 2, 733-746

Mariuzza, R. A., and Poljak, R. J. (1993) Curr. Opinion Immunol. 5, 50-55

Navaza, J. (1994) Acta Crystallogr. 50, 157-163

Padlan, E. A., Silverton, E. W., Sheriff, S., Cohen, G. H., Smith-Gill, S. J., and Davies, D. R. (1989) Proc. Natl. Acad. Sci. U. S. A. 86, 5938-5942

Pellegrini, M., and Doniach, S. (1993) Proteins 15, 436-444

Sanz, I., and Capra, J. D. (1987) Proc. Natl. Acad. Sci. U. S. A. 84, 1085-1089

SERC Daresbury Laboratory (1986) Collaborative Computing Project 4. A Suite of Programs for Protein Crystallography. SERC Daresbury Laboratory, Warrington, United Kingdom

Sheriff, S., Silverton, E. W., Padlan, E. A., Cohen, G. H., Smith-Gill, S. J., Finzel B. C., and Davies, D. R. (1987) Proc. Natl. Acad. Sci. U. S. A. 84, 8075-8079 Siekevitz, M., Huang, S., and Gefter, M. (1983) Eur. J. Immunol. 13, 123-132

Smith-Gill S J Lavoie T B and Mainhart, C. R. (1984) J. Immunol 384-393 Taub, R., and Greene, M. I. (1992) Biochemistry 31, 7431-7435

Tello, D., Spinelli, S., Souchon, H., Saul, F. A., Riottot, M.-M., Mariuzza, R. A., Lascombe, M.-B., Houdusse, A., Eisele, J.-L., Fischmann, T., Chitarra, V., Boulot, G., Bhat, T. N., Bentley, G. A., Alzari, P. M., and Poljak, R. J. (1990) Biochimie (Paris) 72, 507-512

Tello, D., Goldbaum, F. A., Mariuzza, R. A., Ysern, X., Schwarz, F. P., and Poljak, R. J. (1993) Biochem. Soc. Trans. 21, 943-946

Tonegawa, S. (1983) Nature 302, 575-581

Van Regenmortel, M. H. V. (1989) Immunol. Today 10, 266-272

Wilson, I. A., and Stanfield, R. L. (1993) Curr. Opin. Struct. Biol. 3, 113-118 